\title{
117 Ritz 法による立方異方性回転リングの弾性力学解析
}

\section{Elastic Amalysis of a Rotating Ring with Cubic Anisotropy by Ritz Method}

\author{
○正 小河昭紀 （航技研） 正 周風華(Johns Hopkins Univ.) \\ Akinori OGAWA, National Aerospace Laboratory, 7-44-1 Jindaijihigashi, Chofu, Tokyo, JAPAN \\ Fenghua ZHOU, Johns Hopkins University, 232 Latrobe Hall, Baltimore, Maryland, 21218, USA
}

\begin{abstract}
Thin, ring-shape disks are used as the standard specimens in spin tests. To investigate the deformation/failure behaviors of the specimen under centrifugal loading, stress analysis of the rotating disk is necessary. Although there are many analyses about isotropic or cylindrical anisotropic rotating disks, no closed-form solution is found for rotating rings with Cartesian anisotropy. In this paper, an approximate analyzing approach based on Ritz's method is proposed to analyze the deformation characteristics of a cubic anisotropic ring under centrifugal loading. Approximate expressions of displacement components are proposed, which contain 15 unknown coefficients. The potential energy of the disk is calculated. By using variation theory, the unknown coefficients are solved and the disk's deformation behavior becomes known. Analytical results from present approach are compared to FEM's. It is found that the displacement results from both analyses agree very well, with error less than $1 \%$. The major stress component results agree well with each other, too.
\end{abstract}

Key Words: Rotating disk, Cubic anisotropy, Single crystal, Cross Laminate, Approximate analysis, Ritz method

\section{1. 緒言}

回転円盤はターボ機械、遠心機器等の重要な部品であり、 又、中空円盤は材料の回転試験（スピンテスト）に標準試験 片として用いられる[1]。遠心力を受ける円盤の力学解析は、 実用部品の設計、或は材料回転試験結果の解釈に必要とされ る。等方性回転円盤の弾性解析は容易で、その結果は一般材 料力学教科書またはハンドブックに記載されている[2, 3]。一 方、複合材料製円盤は通常、異方性を持つため、解析は複雑 である。その中で、絾維が円周方向または半径方向に入った 円盤は円柱異方性（Cylindrical Anisotropy）を有す。遠心 力を受ける場合、円盤の変形は軸対称であり、厳密な数式解 析は可能である。現在、円柱異方性回転円盤の力学解析は多

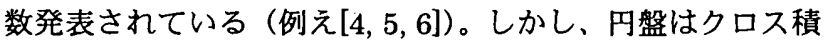
層複合材料または結晶制御材料で製造された場合、材料特性 はデカルト異方性（Cartesian Anisotropy）になる。このよ うな材料の回転円盤の数式解析は困難であり、筆者らの知る 限り、現在 Closed-Form の解析はまだ存在しない。

デカルト異方性材料の中で、材料主軸である X、Y および $\mathrm{Z}$ 軸方向で同じ弾性常数を有する所謂立方異方性材料は重要 な一分野である。単結晶材料と、0/90 積層板或は平織り積層 板等の複合材料は、典型的な立方異方性材料である。筆者ら は、中実、立方異方性回転円盤の平面応力理論解析を行い、 厳密的な理論解を見出した[7]。その結果により、中実立方異 方性円盤内部の応力分布は回転軸（Z 軸）に関して対称であ る事を示した。本論は、まず、立方異方性材料の構成式、及 び典型的な立方異方性材料（単結晶類及び複合材料類）の特 徴を表すパラメータを定義する。そして、前報中実回転円盤 の解析結果を踏まえ、内、外直径比 1:1.6の中空円盤(スピン テス卜試験片形状)の応力解析を行う。立方異方性中空円板 の問題では、厳密な数式解は困難であるため、本論では、 Ritz 型の近似理論解析手法を提案した。Ritz 法の解析結果 と FEM 解析結果を比較して、両者は良く一致することを確 認した。この解析方法は、FEMに比較して、容易に立方異 方性中空円板の弾性力学解析に適用可能と思われる。

\section{2. 問題の定義及び材料特性值}

図 1 に本論が扱う円盤を示す。 中空円盤は中心に位置する回転 軸（Z 軸）回りを、 $\omega$ の角速度 で回転する。円盤材料は密度 $\rho$ の立方異方性弾性体である。材 料の主軸を X,Y 軸として、直角 座標系及び極座標系を想定する

（図 1)。平面応力の場合、材料

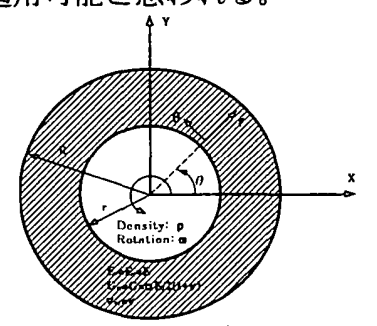

Fig. 1 A Rotating Ring
の弾性構成式は次の式で表わされる：

$$
\left\{\begin{array}{l}
\sigma_{x} \\
\sigma_{y} \\
\tau_{x y}
\end{array}\right\}=\tilde{E}_{0}\left\{\begin{array}{c}
\varepsilon_{x} \\
\varepsilon_{y} \\
\gamma_{x y}
\end{array}\right\}=\frac{E}{1-v^{2}}\left[\begin{array}{ccc}
1 & v & 0 \\
v & 1 & 0 \\
0 & 0 & \frac{\left(1-v^{2}\right) G}{E}
\end{array}\right]\left\{\begin{array}{l}
\varepsilon_{x} \\
\varepsilon_{y} \\
\gamma_{x y}
\end{array}\right\}
$$

材料の独立した工学係数 (Technical Constants) は E.G. vはである。本論では、材料の異方性を表すパラメーター $\alpha$ を、次のように定義する : $\alpha=2(1+v) G / E$ 典型的な超耐熱材料の $\alpha$ データを表 1 に示す。

Table 1 Elastic constants of representative HT materials

\begin{tabular}{|c|c|c|c|c|c|}
\hline Material & E/Gpa & G/Gpa & $v$ & $\alpha$ & Ref \\
\hline 0/90C/C (T300/UD) & 59 & 6 & 0.07 & 0.217 & {$[1]$} \\
\hline 0/90C/C (UM46/UD) & 127 & 7 & 0.00 & 0.110 & {$[1]$} \\
\hline 0/90C/C (T800/UD) & 137 & 7.5 & 0.01 & 0.111 & {$[8]$} \\
\hline Hastelloy-X (SC) & 121.5 & 118.7 & 0.683 & 3.28 & {$[9]$} \\
\hline PWA 1480 (SC) & 144.4 & 129.3 & 0.650 & 2.96 & {$[9]$} \\
\hline TMS-75 (SC) & 149.0 & 132 & 0.629 & 2.88 & {$[10]$} \\
\hline
\end{tabular}

表 1 のデータによると、通常、(0/90)積層 $\mathrm{C} / \mathrm{C}$ 複合材料は $\alpha<1$ ( $0.1 \sim 0.2$ 程度) ; 単結晶材料は、 $\alpha>1$ (2 4程度)である。 ちなみに等方性材料は $\alpha=1$ になる。

3. 中実回転円盤内部の応力分布 ([7])

中実回転円盤 : $a=0, b=R$ の場合、前報で縓密的な理論解 を見出した $[7]$ 。円盤内部、極座標 $(r, \theta)$ 点の変位、ひずみ、ま たは応力（極座標系での成分）は下の、(3.1-3.3)式で表す：

$u_{r}=\frac{(1-v) \rho \omega^{2} r}{4 E(1+3 \alpha+v-\alpha v)}\left[2(1+2 \alpha+v) R^{2}-(1+\alpha)(1+v) r^{2}+\frac{(1-\alpha)(1+v)}{3} r^{2} \operatorname{Cos} 4 \theta\right]$ $u_{\theta}=-\frac{\left(1-v^{2}\right)(1-\alpha) \rho \omega^{2}}{12 E(1+3 \alpha+v-\alpha v)} r^{3} \operatorname{Sin} 4 \theta$

$\varepsilon_{r}=\frac{(1-v) \rho \omega^{2}}{4 E(1+3 \alpha+v-\alpha v)}\left[2(1+2 \alpha+v) R^{2}-3(1+\alpha)(1+v) r^{2}+(1-\alpha)(1+v) r^{2} \operatorname{Cos} 4 \theta\right]$ $\varepsilon_{\theta}=\frac{(1-v) \rho \omega^{2}}{4 E(1+3 \alpha+v-\alpha v)}\left[2(1+2 \alpha+v) R^{2}-(1+\alpha)(1+v) r^{2}-(1-\alpha)(1+v) r^{2} \operatorname{Cos} 4 \theta\right]$ $\gamma_{r \theta}=-\frac{\left(1-v^{2}\right)(1-\alpha) \rho \omega^{2} r}{2 E(1+3 \alpha+v-\alpha v)} \sin 4 \theta$

$\sigma_{r}=\frac{(1+2 \alpha+v)\left(R^{2}-r^{2}\right)}{2(1+3 \alpha+v-\alpha v)} \rho \omega^{2} \quad, \quad \tau_{r \theta}=0 \quad$ (3.1,3.2,3.3)

$\sigma_{\theta}=\frac{(1+2 \alpha+v) R^{2}-(1+v+2 \alpha v) r^{2}}{2(1+3 \alpha+v-\alpha v)} \rho \omega^{2}$

上式から、立方異方性中実円盤が遠心力を受ける場合、円 盤内部の変位、歪み分布は軸対称でないが、円盤内部の応力 は(1) $r \theta$ 面のせん断応力はゼロであり、(2) 周方向及び半径 方向の主応力は $\theta$ 座標に依存しない、等の理由から、Z 軸に 


\section{関して軸対称である事が示される。}

\section{4. 中空円盤の解析 : Ritz 解析方法}

図 1 に示した中空円盤は内、外とも境界があるため、厳 密解は困難である。ここで近似数式解析を試みる。まず材料 の弾性構成式(1)を極座標系へ変換する：

$\left\{\begin{array}{c}\sigma_{r} \\ \sigma_{\theta} \\ \tau_{r \theta}\end{array}\right\}=\tilde{E}(\theta)\left\{\begin{array}{c}\varepsilon_{r} \\ \varepsilon_{\theta} \\ \gamma_{r \theta}\end{array}\right\}=\frac{E}{4\left(1-v^{2}\right)}\left[\begin{array}{ccc}c_{r r} & c_{r \theta} & c_{r s} \\ & c_{\theta \theta} & c_{\theta s} \\ S y m . & & c_{s s}\end{array}\right]\left\{\begin{array}{c}\varepsilon_{r} \\ \varepsilon_{\theta} \\ \gamma_{r \theta}\end{array}\right\}$

弾性マトリクス $\tilde{E}(\theta)$ の各成分は（5）式で与えられる：

$c_{r r}=c_{\theta \theta}=3+\alpha+(1-\alpha) v+(1-\alpha)(1-v) \operatorname{Cos} 4 \theta$

$c_{r \theta}=-1+\alpha-(3+\alpha) v+(1-\alpha)(1-v) \operatorname{Cos} 4 \theta$

$c_{r s}=-(1-\alpha)(1-v) \operatorname{Sin} 4 \theta$

$c_{\theta s}=(1-\alpha)(1-v) \operatorname{Sin} 4 \theta$

$c_{\mathrm{ss}}=(1-v)[1+\alpha-(1-\alpha) \operatorname{Cos} 4 \theta]$

円環は遠心力を受けると、 $r$-及び $\theta$-方向の変形関数をそれ ぞれ $u_{r}(r, \theta)$ と $u_{\theta}(r, \theta)$ で表すと、環内部の歪み成分は：

$$
\varepsilon_{r}=\frac{\partial u_{r}}{\partial r}, \varepsilon_{\theta}=\frac{u_{r}}{r}+\frac{\partial u_{\theta}}{r \partial \theta}, \gamma_{r \theta}=\frac{\partial u_{r}}{r \partial \theta}+\frac{\partial u_{\theta}}{\partial r}-\frac{u_{\theta}}{r}
$$

であり、系全体のポテンシャルエネルギーは式(7)になる。

$$
W=\int_{r-a}^{b} \int_{\theta=0}^{2 \pi} r \Psi(r, \theta) d r d \theta
$$

ここ $\Psi$ 系のポテンシャル密度で、次の 2 項に分けられる。 $\Psi=\Psi_{e}+\Psi_{\omega}$

$\Psi_{\mathrm{e}}$ 及び $\Psi_{\omega}$ はそれぞれ板の内部変形及び遠心力荷重による ポテンシャル密度で、それぞれ式(9)で計算する。

$\Psi_{e}=\frac{1}{2}\left\{\varepsilon_{r}, \varepsilon_{\theta}, \gamma_{r \theta}\right\}[\tilde{E}(\theta)]\left\{\varepsilon_{r}, \varepsilon_{\theta}, \gamma_{r \theta}\right\}^{T}, \Psi_{\omega}=-\rho \omega^{2} u_{r}$

変形関数の形式が与えられれば、系のポテンシャルWの最 小值化の条件で、板の形状変形関数が計算される。

\section{5. 形状変形関数及び解析結果}

立方異方性中実円盤の解析解(式 3)、等方性円盤の解析解 $[2$, 3]、及び立方異方性円環の FEM 試算結果等を考慮して、立 方異方性円環の変位関数は近似的に次の式で表せる。：

$$
\begin{aligned}
u_{r}= & \left(a_{1} r^{-3}+a_{2} r^{-1}+a_{3} r+a_{4} r^{3}+a_{5} r^{5}\right) \\
& +\left(b_{1} r^{-3}+b_{2} r^{-1}+b_{3} r+b_{4} r^{3}+b_{5} r^{5}\right) \operatorname{Cos}(4 \theta) \\
u_{\theta}= & \left(c_{1} r^{-3}+c_{2} r^{-1}+c_{3} r+c_{4} r^{3}+c_{5} r^{5}\right) \operatorname{Sin}(4 \theta)
\end{aligned}
$$

ここ、 $a_{i} 、 b_{i} 、 c_{i}(i=1, . .5)$ は末知常数で、全部で 15 個ある。

外・内径比は $1.6 （ \mathrm{a}=1, \mathrm{~b}=1.6) 、 \rho \omega^{2}=1$ の場合計算した 円盤の変位分布は図 2 に示す。材料の異方性パラメーターが 異なると、円盤内部の最大変位の值と発生する場所は異なる ことが示される。式(6)と(4)を用い、円盤内部のひずみ及び 応力分布を同様に計算できるが、掲載を省略する。
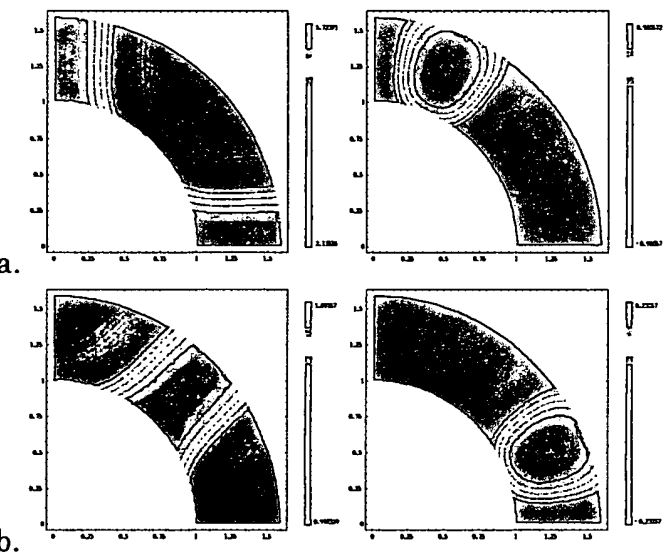

Fig. 2 Displacement $\left(u_{r}, u_{\theta}\right)$ distribution in a rotating ring: (a) $\alpha=0.2, v=0.1$; (b) $\alpha=3, v=0.6$
6. Ritz 法解析結果と FEM 法解析結果との比較

Ritz 法と FEM 法を計算した結果、回転円盤内部の変位、

\begin{tabular}{|c|c|c|c|c|c|c|c|}
\hline \multirow[t]{2}{*}{$\alpha$} & \multirow[t]{2}{*}{$v$} & \multicolumn{2}{|c|}{$\mathrm{u}_{\mathrm{r}}(\max )$} & \multicolumn{2}{|c|}{$\mathrm{u}_{\mathrm{r}}(\mathrm{min})$} & \multicolumn{2}{|c|}{$\mathrm{u}_{\theta}(\max )$} \\
\hline & & Ritz & FEM & Ritz & FEM & Ritz & FEI \\
\hline .1 & 0.1 & .0609 & 10. & & & 528 & 2.156 \\
\hline 1.2 & 0. & & & & & & .95 \\
\hline .5 & 0. & & 3 & $\underline{9}$ & & .2615 & 0.2611 \\
\hline$\lambda$ & 0.8 & 37 & 2.287 & 88 & 2.0 & $\underline{0}$ & 0 \\
\hline 2.0 & 0.6 & 19 & 2.022 & 1.2063 & 1.206 & 0.1746 & 0.1744 \\
\hline 3.0 & 0. & & 1.8 & 0.9924 & 0.9922 & 0.2327 & 0.2320 \\
\hline & & & .7 & & & & \\
\hline
\end{tabular}
ひずみ及び応力分布はほぼ同じである。無次元化した変位、 応力の最大值及び最小值をそれぞれ表 2 、表 3 に示す。

Table 2 Comparison of displacement results of Ritz and FEM analyses

Table 3 Comparison of stress results of Ritz and FEM analyses

\begin{tabular}{|c|c|c|c|c|c|c|c|}
\hline$\alpha$ & $v$ & \multicolumn{2}{|c|}{$\sigma_{\mathrm{r}}(\mathrm{max})$} & \multicolumn{2}{c|}{$\sigma_{\theta}(\max )$} & \multicolumn{2}{c|}{$\sigma_{\theta}(\min )$} \\
\cline { 3 - 8 } & & Ritz & FEM & Ritz & FEM & Ritz & FEM \\
\hline 0.1 & 0.1 & 0.3385 & 0.358 & 4.2906 & 4.241 & 0.7628 & 0.667 \\
\hline 0.2 & 0.1 & 0.2289 & 0.242 & 3.1834 & 3.184 & 0.9706 & 0.923 \\
\hline 0.5 & 0.2 & 0.1675 & 0.180 & 2.5279 & 2.534 & 1.1584 & 1.150 \\
\hline 1 & 0.3 & 0.1485 & 0.154 & 2.287 & 2.293 & 1.273 & 1.274 \\
\hline 2.0 & 0.6 & 0.1741 & 0.194 & 2.6038 & 2.618 & 1.1025 & 1.091 \\
\hline 3.0 & 0.6 & 0.1872 & 0.201 & 2.7479 & 2.754 & 1.0850 & 1.063 \\
\hline 5.0 & 0.7 & 0.2256 & 0.236 & 3.1430 & 3.141 & 0.9869 & 0.942 \\
\hline
\end{tabular}

Ritz 法で計算した円盤の変位值は、FEM 数值計算結果と

一致する（誤差 $<0.5 \%$ )。これは、仮定した変形関数の形式(式 10)は妥当であることを裏付けている。

Ritz 法計算した周方向応力 $\left(\sigma_{\theta}\right)$ の最大值は、数值計算結 果とほぼ一致する (誤差 $<2 \%)$ が、半径方向の応力成分 $\left(\sigma_{\mathrm{r}}\right)$ 、 及び $\sigma_{\theta}$ の最小值では一定の誤差（8\%以内）が存在する。こ の誤差は、Ritz 法の近似性、及び FEM 法の応力計算精度等 の両方の要因によるものと考える。

\section{7. 結論}

本論は、立方異方性中空回転円盤(スピンテスト試験片形 状)の応力解析を試み、以下の結論を得た：

(1) 単結晶金属と[0/90]積層複合材料が代表する立方異方性 材料の特性パラメー夕による整理（表 1 ）を提案した ;

(2) Ritz 型の近似理論解析手法を提案し、中空円盤の応力解 析を行った。遠心力を受ける立方異方性中空円盤の変形 は、近似的に(式 10)で表せる；

(3) Ritz 法の解析結果と FEM 解析結果を比較して、両者は よく一致し、本論の解析方法の有効性を確認した。

立方異方性中空回転円盤の解析結果はスピンテスト実験 結果の解釈及び材料強度の評価に適用される。

\section{8. 謝辞}

本研究が行うにあたって、東京大学工学部塩谷義先生から 有益の助言をいただき、ここで感謝の意を表します。

9. 参考文献

(1) 小河昭紀、他 3 名、“ $\mathrm{C} / \mathrm{C}$ 材 $(0 / 90)$ 及び $0 / 45 / 90$ 栍層)回転円薙のひずみ特 性”、第 11 回カスタービン秋季满演会、pp267-270、1996

(2) Timoshenko, S. and Goodier, J. N., Theory of Elasticity, 3rd Ed. pp80-83, McGraw-Hill, New York, 1970

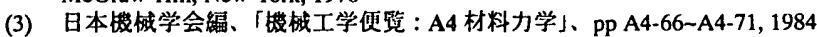

(4) Tang, S., "Elastic stresses in rotating anisotropic disks", Int. J. Mech. Sci., 11, pp509-517, 1969

(5) Leissa, A. W. and Vagins, M. "The design of orthotropic materials for stress optimization", Int. J. Solids Structures, 14, pp517-526, 1978

(6) Jain, R., Ramachandra, K. and Simha, K. R. Y., "Rotating anisotropic disc of uniform strength", Int. J. Mech. Sci., 41, pp639-648, 1999

(7) Fenghua Zhou and Akinori Ogawa, "Elastic Solutions of a Solid Rotating Disk with Cubic Anisotropy", J. Applied Mechanics, To be published

（8）周風菲、他 2 名、“ “Off-Axis 試駼に上る一方向㤝化 $\mathrm{C} / \mathrm{C}$ 複合材料の面内㟋 性常数について”、第 27 回 FRP シンボジウム、pp49-52, 1998

(9) Canistaro, et.al., "Elastic constants of single crystal Hastelloy X at elevated temperatures", J. Engn Mater \& Tech., Trans ASME, Vol.120, pp242.2 47, 1998

(10) 金属材料技術研究所、TMS - 75 データシート。 